\title{
Measuring fear of movement/(re)injury in chronic low back pain patients using implicit measures.
}

Citation for published version (APA):

Leeuw, M., Peters, M. L., Wiers, R. W. H. J., \& Vlaeyen, J. W. S. (2007). Measuring fear of movement/(re)injury in chronic low back pain patients using implicit measures. Cognitive Behaviour Therapy, 36, 52-64. https://doi.org/10.1080/16506070601070400

Document status and date:

Published: 01/01/2007

DOI:

10.1080/16506070601070400

Document Version:

Publisher's PDF, also known as Version of record

Document license:

Taverne

\section{Please check the document version of this publication:}

- A submitted manuscript is the version of the article upon submission and before peer-review. There can be important differences between the submitted version and the official published version of record.

People interested in the research are advised to contact the author for the final version of the publication, or visit the DOI to the publisher's website.

- The final author version and the galley proof are versions of the publication after peer review.

- The final published version features the final layout of the paper including the volume, issue and page numbers.

Link to publication

\footnotetext{
General rights rights.

- You may freely distribute the URL identifying the publication in the public portal. please follow below link for the End User Agreement:

www.umlib.nl/taverne-license

Take down policy

If you believe that this document breaches copyright please contact us at:

repository@maastrichtuniversity.nl

providing details and we will investigate your claim.
}

Copyright and moral rights for the publications made accessible in the public portal are retained by the authors and/or other copyright owners and it is a condition of accessing publications that users recognise and abide by the legal requirements associated with these

- Users may download and print one copy of any publication from the public portal for the purpose of private study or research.

- You may not further distribute the material or use it for any profit-making activity or commercial gain

If the publication is distributed under the terms of Article $25 \mathrm{fa}$ of the Dutch Copyright Act, indicated by the "Taverne" license above, 


\section{Measuring Fear of Movement/(Re)injury in Chronic Low Back Pain Using Implicit Measures}

\section{Maaike Leeuw, Madelon L. Peters, Reinout W. Wiers \& Johan W. S. Vlaeyen}

To cite this article: Maaike Leeuw, Madelon L. Peters, Reinout W. Wiers \& Johan W. S. Vlaeyen (2007) Measuring Fear of Movement/(Re)injury in Chronic Low Back Pain Using Implicit Measures, Cognitive Behaviour Therapy, 36:1, 52-64, DOI: 10.1080/16506070601070400

To link to this article: https://doi.org/10.1080/16506070601070400

\section{Published online: 09 Mar 2007.}

Submit your article to this journal $\sqsubset$

Џll Article views: 204

Q View related articles $\asymp$

4 Citing articles: 1 View citing articles 


\title{
Measuring Fear of Movement/(Re)injury in Chronic Low Back Pain Using Implicit Measures
}

\author{
Maaike Leeuw ${ }^{1}$, Madelon L. Peters ${ }^{1}$, Reinout W. Wiers ${ }^{2}$ and \\ Johan W. S. Vlaeyen ${ }^{1}$ \\ ${ }^{1}$ Department of Medical, Clinical and Experimental Psychology, Faculty of Psychology, and \\ ${ }^{2}$ Department of Experimental Psychology, Faculty of Psychology, Maastricht University, \\ Maastricht, The Netherlands
}

\begin{abstract}
Fear of movement/(re)injury is assumed to contribute to the development and maintenance of chronic low back pain (CLBP) in a subgroup of patients. Studying fear of movement/(re)injury with implicit attitude measures, without the awareness of the patient, might be a valuable addition to self-report questionnaires. The aims of the current study were to investigate whether CLBP patients demonstrate more implicit fear of movement/(re)injury than healthy controls, and whether 2 implicit measures are related to each other, and to an explicit self-report measure of fear of movement/ (re)injury. A group of 66 CLBP patients and 30 healthy controls took part in this study. In addition to self-report questionnaires, fear of movement/(re)injury was implicitly assessed by the Extrinsic Affective Simon Task (EAST) and the Go-No-Go-Association Task (GNAT) that aimed to determine the association between back-stressing movements and the evaluation "threatening". On both implicit tasks it was found that neither CLBP patients nor healthy controls demonstrated implicit fear of movement/(re)injury, and that CLBP patients did not differ from healthy controls in their level of implicit fear of movement/(re)injury. In general, no associations were found between the EAST and the GNAT, or between implicitly measured and self-reported fear of movement/ (re)injury. One major caveat in drawing inferences from these findings is the poor reliability of these implicit measures. Research towards the psychometric properties of these measures should first be expanded before modifying, and applying, them to more complex domains such as fear of movement/(re)injury. Key words: pain-related fear; implicit measures; Extrinsic Affective Simon Task; Go-no-Go Association Task; low back pain; reliability
\end{abstract}

Received 19 June, 2006; Accepted 19 September, 2006

Correspondence address: Maaike Leeuw, Department of Medical, Clinical and Experimental Psychology, Faculty of Psychology, Maastricht University, PO Box 616, 6200 MD, Maastricht, The Netherlands. Tel: +31 43 3881600; Fax: +31 43 3884155.E-mail: M.Leeuw@DMKEP.Unimaas.nl

Of the many people suffering from low back pain (LBP), only a few develop chronic low back pain (CLBP) (Waddell, 2004). A cognitive behavioural account assigns a prominent role to pain-related fear in explaining the development and maintenance of CLBP in a subgroup of these patients (Lethem, Slade, Troup, \& Bentley, 1983; Vlaeyen, Kole Snijders, Rotteveel, Ruesink et al., 1995). The detrimental contribution of pain-related fear in the development and maintenance of LBP has been demonstrated in currently pain-free people (e.g. Linton, Buer, Vlaeyen, \&
Hellsing, 1999; Picavet, Vlaeyen, \& Schouten, 2002; Van Nieuwenhuyse et al., 2006), in acute LBP patients (e.g. Burton, McClune, Clarke, \& Main, 2004; Picavet et al., 2002; Swinkels-Meewisse, Roelofs, Schouten, Verbeek, Oostendorp, \& Vlaeyen, 2006) and in CLBP patients (e.g. Al-Obaidi Al-Zoabi, Al-Shuwaie, Al-Zaabie, \& Nelson, 2003; Geisser, Haig, \& Theisen, 2000; Goubert, Crombez, \& Lysens, 2005). The effectiveness of treatments targeted at decreasing pain-related fear may also emphasize its contribution to disability in some 
patients (e.g. Boersma et al., 2004; de Jong et al., 2005; Vlaeyen, de Jong, Geilen et al., 2002). Pain-related fear is a rather general construct, encompassing various specific fears, depending on the source to which the fear is directed. One of these specific fears, to which extensive research has been directed, is fear of movement/(re)injury that signifies the fear that physical activities and movement will cause (re)injury to the back.

Most research on pain-specific beliefs is based on self-report measures, which may be susceptible to self-presentational strategies, and may be suitable only to measure beliefs that require a certain amount of conscious reflection and introspection (de Houwer, 2002, 2003b; Fazio \& Olson, 2003). Conscious reflection might be lacking in fearful CLBP patients, who often perceive their disability as a consequence of their pain rather than fear of movement/(re)injury (Vlaeyen, de Jong, Sieben et al., 2002). Implicit attitude measures are suggested to be a promising method to overcome certain limitations of self-report measures, although it should be recognized that they should only be conceived as valuable additional tools and not as a replacement (e.g. de Houwer, 2002; de Jong, Pasman, Kindt, \& Hout, 2001; Gheldof, de Jong, Vinck, \& Houben, 2004). Implicit measures aim to measure evaluations or associations that are automatically activated without the awareness or control of the participant. They often consist of reaction time paradigms, during which a response is required to words that are related to the association of interest. Implicit associations are assumed to be reflected in respectively facilitated or hampered task performance on trials that are compatible or incompatible with the underlying association (e.g. de Houwer, 2003b). Most studies report no, or only moderate, relationships between implicit and self-report measures (Fazio, Jackson, Dunton, \& Williams, 1995; Fazio \& Olson, 2003; Greenwald, McGhee, \& Schwartz, 1998; Nosek \& Banaji, 2001; Teige, Schnabel, Banse, \& Asendorpf, 2004). This discordance can be explained by the dual process MODE model (in which MODE is an acronym for motivation and opportunity as determinants of whether the attitude-to-behaviour process is primarily spontaneous or deliberative in nature; Fazio \& Olson, 2003), through its proposition that responses to self-report measures are influenced by deliberative processes due to the presence of abundant motivation, time and recourses, while the responses of implicit measures rely on automatically activated processes because motivation and time are absent. Meta-analytical findings indicate that correlations between self-report and implicit measures systematically increased when either spontaneity in selfreport measurement was enhanced or when the conceptual overlap between these measures was high (Hofmann Gawronski, Gschwendner, Le, \& Schmitt, 2005).

To date, only 2 studies have investigated implicit attitudes of CLBP patients, demonstrating ambiguous results. De Jong and Peters (2002) showed that high fearful CLBP patients displayed stronger associations between pain and threat than did low fearful subjects on a Word Simon Task. Another study, using the Affective Priming Task, demonstrated a negative evaluation of backstressing movements in pain-free participants, whereas no such negative evaluation was found for CLBP patients (Goubert, Crombez, Hermans, \& Vanderstraeten, 2003). The investigated associations in these studies, however, do not reflect the main association we think underlies fear of movement/(re)injury, namely the evaluation of back-stressing movements as being threatening because of their potential to induce (re)injury to the back.

The current study aimed to examine implicit fear of movement/(re)injury in CLBP patients using 2 implicit measures that determined the association between back-stressing movements and the evaluation "threatening". The first task concerned the Extrinsic Affective Simon Task (EAST: de Houwer, 2003a), which was chosen because of its ability to measure different associations within the same task. Due to its relatively few applications, and low reliability (de Houwer, 2003a; Teige et al., 2004), the Go-No-Go Association Task (GNAT: Nosek \& Banaji, 2001) was added because of its comparatively large effect size. First, we sought to investigate whether CLBP patients demonstrate more implicit fear of movement/(re)injury than healthy controls on the EAST and GNAT. Secondly, we determined whether these 2 implicit measures are related to each other, and to self-reported fear of movement/(re)injury. 


\section{Method}

\section{Participants}

A sample of 66 CLBP patients and 30 healthy controls was included. Exclusion criteria were illiteracy, dyslexia, colour blindness, and a native language other than Dutch. The CLBP patients were selected from several sources $(n=38$ from a randomized clinical trial of Maastricht University; $n=12$ from a work reintegration service; $n=13$ from participation in a previous study; $n=3$ from responses to a poster pamphlet). For all patients the main complaint concerned CLBP for more than 3 months (mean duration 10.75 years, SD 9.18, range $0.5-38$ years). Furthermore, they had to report at least some disability due to back pain, as indicated by a score of 3 or higher on the Roland Disability Questionnaire (Roland \& Morris, 1983). The healthy controls were selected because of their participation in previous experiments at Maastricht University. They were included if they did not have a current pain problem or treatment, and had not experienced LBP in the past year. This group was matched for age, gender, and educational level with the patient group.

\section{Procedure}

The study was introduced as investigating differences in information processing between pain patients and pain-free people. Verbal and written information was provided about the study. Informed consent was obtained before participation. All participants first performed the EAST, followed by the GNAT. Subsequently, they had to assess to what degree they considered the words of the implicit tasks as threatening. Finally, they completed several self-report questionnaires. Patients scheduled for treatment were tested prior to the start of treatment, or in the first 2 weeks of treatment. All participants received a gift voucher and reimbursement of travel expenses for their participation.

\section{Materials}

\section{Implicit measures.}

EAST. The EAST (de Houwer, 2003a) measures the strength of associations between certain concepts and attributes by means of a response time paradigm. Participants have to give a response "positive" or "negative", based on the colour of words, while the valence of that specific word has to be ignored. The underlying idea is that the performance should be superior on trials in which the valence of the correct response matches the meaning of the coloured word than on trials in which the valence of the word and the correct response are opposite to each other. For example, it should be easier to press the "positive" key than the "negative" key in response to "flower", because of the universal positive evaluation of flowers (de Houwer, 2003a).

For the current study, the EAST was adapted to measure fear of movement/(re)injury. Instead of the positive and negative evaluations that were used in the original EAST, and in the study of Goubert et al. (2003), the evaluations "threatening" and "neutral" were chosen as the most suitable associations with back-stressing movements. For exploratory reasons, rest words and injury words were also included in the task. Participants were requested to respond as fast and accurately as possible, by pressing the appropriate response key, to words that appeared in the middle of the computer screen. In the first practice block, white words (threatening and neutral) were presented, for which the correct response had to be based on the meaning of the word. Through this, one threatening and one neutral key were extrinsically generated. During the second practice block, coloured words (back-stressing movement words, rest words, and injury words) appeared in a green or blue colour, for which the response had to be based on the colour of the word. Coloured words therefore had to be responded to by either the threatening or neutral key, depending on the colour, and not the meaning, of the word. In the final actual test phase, these white and coloured words were presented interchangeably, with white words requesting a response based on their meaning and coloured words on the basis of their colour.

Implicit fear of movement/(re)injury should be reflected in a stronger association between back-stressing movements and the evaluation "threatening" than "neutral". Henceforth, associations corresponding to fear of movement/(re)injury will be referred to as compatible (pressing the threatening key in response to movement words), whereas associations non-equivalent to fear of movement/(re)injury will be referred to as incompatible (pressing 
the neutral key in response to movement words). By presenting each coloured word once in green and once in blue, for each word a compatible trial and an incompatible trial existed. An implicit association is reflected in better performance (faster response times and less errors) on compatible trials, and in decreased performance (longer response times and more errors) on incompatible trials.

The first practice block comprised 24 trials; 6 neutral (mineral, normal, objective, modern, owner, and adult) and 6 threatening (fatal, warning, dangerous, terrible, mean, and horrible) words were presented twice. The second practice block comprised 36 trials; 6 backstressing movements (bending, lifting, jumping, falling, pushing, running), 6 injury words (operation, disabled, damage, injury, stab, paralysed) and 6 rest words (resting, sleeping, lying, relaxed, calmness, easiness) were presented once in green and once in blue. The test phase comprised 60 trials; both the coloured and white words were presented twice, each coloured word once in green and once in blue. The words were presented after the presentation of a fixation dot during $500 \mathrm{~ms}$. The response window was $2500 \mathrm{~ms}$, after which the absence of a response was registered as a non-response. The inter trial interval was $1000 \mathrm{~ms}$. When a response was shorter than $300 \mathrm{~ms}$ the message "too fast" appeared on the screen. In case of an error, "false" emerged in the screen until the accurate response was made. The assignment of the response keys to both the meaning and the colour of the words were counterbalanced between participants, resulting in 4 different EAST versions. For each version, the same word sequence was presented during the 2 practice blocks, while different word sequences were presented during the test phase of each version.

GNAT. The GNAT (Nosek \& Banaji, 2001) is another response time paradigm to measure implicit associations, by assessing the strength of an association between a certain concept and 2 attributes. During the GNAT several phases are presented. In each phase, different concepts are combined with different attributes. Due to this, both highly related and less related concepts and attributes are presented in different phases (e.g. "flower" can be combined with "good" in one phase and with "bad" in another). Participants have to press a key (GO) to stimuli belonging to pre-defined concept-attribute pairings, and do not have to press a key (NO GO) to stimuli that do not belong to either of these categories (e.g. pressing the key to words belonging to the categories "flower" and "good", and not to "bugs" and "bad"). Performance should be superior when the key has to be pressed for a concept and attribute that are highly associated than when the key has to be pressed for a concept and attribute that are not, or less, associated with each other. For example, superior performance is expected when the key has to be pressed in the case of items belonging to the categories "flower" and "good" than when the key has to be pressed for the categories "flower" and "bad".

The GNAT was adapted to measure fear of movement/(re)injury. Back-stressing movement words and geometrical shape words represented the concept categories, while threatening words and neutral words represented the attribute categories. The shape phases were not relevant, but were included to present a neutral context. Participants had to decide as fast and accurately as possible whether they had to respond to words that appeared in the middle of the screen, by pushing a response key, or not to respond at all. The GNAT started with 2 practice tasks, in which participants had to differentiate between neutral words and threatening words, and between back-stressing movement words and geometrical shape words, respectively. After this, 4 actual test phases were presented, during which words from all 4 categories were presented intermixed. These test phases consisted of compatible and incompatible movement categorizations, as well as compatible and incompatible shape categorizations. The test phases of interest for this study concerned the compatible and incompatible movement phases that respectively indicated pressing the key to movement and threatening words, or to movement and neutral words. Based on the hits and false alarms, a sensitivity score was calculated according to the signal detection theory (Nosek \& Banaji, 2001). The magnitude of the sensitivity index reflects the extent to which a concept is associated with an evaluation. Implicit fear of movement should thus be reflected in higher sensitivity on the compatible movement phase than on the incompatible movement phase. 
During the first categorization phase 24 trials were presented: 6 neutral (mineral, normal, objective, modern, owner, adult) and 6 threatening (fatal, warning, dangerous, terrible, mean, horrible) words were presented twice. The second categorization phase also consisted of 24 trials: 6 movement (bending, lifting, jumping, falling, pushing, running) and geometrical shape words (square, triangle, rectangle, circle, oval, cube) were presented twice. In each test phase, the 4 categories of 6 words each were presented, resulting in 48 trials per test phase. The labels of the target categories were displayed in the right and left quadrants of the screen. The colour of both the stimuli and the category labels of the evaluative attributes was white, while the items and category labels of the concepts were displayed in light blue. The words were presented in the middle of the screen and remained there until the correct response was given and the feedback displayed, or until the response deadline was reached. The response window was $950 \mathrm{~ms}$. Correct and incorrect responses were followed respectively by a green circle or a red cross that were presented for $500 \mathrm{~ms}$. The next word appeared $250 \mathrm{~ms}$ after this feedback. Four versions of the GNAT were developed, in which the order of the compatible and incompatible phases was varied. For each phase of the GNAT, a different sequence of words was presented.

Both implicit tasks were programmed using micro-experimental computer software (MEL; Schneider, 1996). Most of the presented words were derived from other studies (de Jong \& Peters, 2002; Houben, Gijsen, Peterson, de Jong, \& Vlaeyen, 2005; Vancleef, personal communication). Others were devised while accounting for the concept of fear of movement/(re)injury as well as the length and number of syllables. All word sequences were generated by a randomization procedure, with the restriction that the same word was not presented directly again after its first presentation, and that the same response was not required more than 3 times in a row. Responses were registered by an external response box (Psychology Software Tools, 1996-2003).

\section{Self-report measures.}

Word appraisal. Of every word that was presented during the implicit tasks, participants were asked to evaluate the threat value on a 10-point self-report rating scale ranging from 1 ("neutral") to 10 ("threatening"). Mean appraisal was computed for each of the word categories. Word appraisal was missing for one patient.

Functional disability. Functional disability was measured in all participants with the Dutch version (Schoppink, van Tulder, Koes, Beurskens, \& de Bie, 1996) of the Quebec Back Pain Disability Scale (QBPDS; Kopec et >al., ). The QBPDS consists of 20 items describing activities commonly affected by back pain, which patients have to rate on a $<$ ?show=to]6-point self-report scale, ranging from "not difficult" to "unable to perform", to what degree they experience difficulties in performing these activities. The reliability and validity of the QBPDS are well established (Fritz \& Irrgang, 2001; Kopec et al., 1995; Schoppink et al., 1996).

Fear of movement/(re)injury. The CLBP patients completed the Dutch version (Vlaeyen et al., 1995) of the Tampa Scale for Kinesiophobia (TSK; Miller et al., 1991) as a measure of fear of movement/(re)injury. The TSK consists of 17 statements that have to be rated on a 4-point scale ranging from "strongly disagree" to "strongly agree". The Dutch version of the TSK has been shown to be sufficiently reliable and valid (Goubert et al., 2004; Roelofs, Goubert, Vlaeyen, \& Crombez, 2004; Swinkels-Meewisse, Swinkels, Verbeek, Vlaeyen, \& Oostendorp, 2003; Vlaeyen, Kole Snijders, Rotteveel et al., 1995). The healthy controls completed the TSK-G, in which all items have been rephrased in such way that people without LBP can also complete them. The TSK-G was demonstrated to have sufficient internal stability and validity both for individuals with and without back pain (Houben, Leeuw, Vlaeyen, Goubert, \& Picavet, 2005). For the TSK and TSK-G, a summation score was calculated after removal of the reversed key items because of too low inter-item correlations (Goubert et al., 2004; Houben, Leeuw et al., 2005).

Pain catastrophizing. The Dutch version (Crombez \& Vlaeyen, 1996) of the Pain Catastrophizing Scale (PCS; Sullivan, Bishop, \& Pivik, 1995) was used to determine catastrophizing about pain. The PCS consists 
of 13 items, on which the patients are asked to indicate on a 5-point scale, ranging from 0 (not at all) to 4 (always), to what degree they experienced certain thoughts or feelings during pain. The Dutch version of the PCS shows good psychometric properties (Van Damme, Crombez, Bijttebier, Goubert, \& Van Houdenhove, 2002; Van Damme et al., 2000).

\section{Statistical analyses}

For each analysis, the skewness statistics of the included variables were examined. In cases where a variable was not normally distributed (skewness statistics below -1.5 , or above 1.5), non-parametric analyses were employed.

The 2 practice blocks of the EAST and the white words of the actual test phase were removed from further analyses. EAST analyses were performed separately for the response latencies and the errors. Only response latencies of correct responses were included. In accordance with Greenwald et al. (1998) response latencies shorter than $300 \mathrm{~ms}$ were recalculated into $300 \mathrm{~ms}$. Log transformations were then performed on the raw latencies. Further analyses were performed with these transformed latencies, except in presenting mean response times. The proportion of errors was calculated by dividing the number of errors by the number of trials on which a response was given (thereby excluding nonresponses). Both the mean response times and the mean proportion of errors were determined for the compatible and incompatible movement trials. Subsequently, an EAST response time score and an EAST error score were calculated by subtracting the mean response latency or proportion of errors in the compatible phase from the mean response latency or proportion of errors in the incompatible phase. By this means, a positive EAST response time score or EAST error score indicated the presence of implicit fear of movement/(re)injury. Since associations with the movement words in the EAST were our main interest, the analyses focused on this word category. Data were analysed separately for the response latencies and errors using analysis of variance (ANOVA) with a 2 (group: CLBP patients vs. healthy controls) $\times 2$ (type of response: compatible movement trials or incompatible movement trials) design. Age, gender, educational level, and self-reported fear of movement/(re)injury were included as covariates.

For analyses with the GNAT, the first 2 practice blocks and the shape phases were removed from further analyses. Sensitivity indices were calculated for both the compatible and incompatible movement phase by the same method as described in Nosek and Banaji (2001). The GNAT movement effect was calculated by subtracting the sensitivity index of the incompatible movement phase from the one in the compatible movement phase. Due to this, a positive score would reflect the presence of implicit fear of movement. The same ANOVA was applied as with the EAST, except that for "type of response" now "phase" (compatible movement or incompatible movement) was included.

To investigate the relationship between implicit measures and self-report measures, analyses were separately performed for CLBP patients and healthy controls, since they were expected to differ. Pearson correlation coefficients were calculated to examine whether the EAST response time effect was related to the EAST error effect, and whether both EAST effects were related to the GNAT effect. Secondly, it was investigated whether implicit fear of movement/(re)injury measured by the EAST and the GNAT were related to selfreport measures of fear of movement/(re)injury, by computing Pearson correlation coefficients with self-reported fear of movement/(re)injury, pain catastrophizing, and the appraisal of movement words.

\section{Results \\ Sociodemographics}

The group descriptives for both the CLBP patients and the healthy controls are shown in Table 1. Gender distribution, age, and education level did not differ significantly between patients and healthy controls. Patients reported significantly more functional disability, more fear of movement/(re)injury, and more pain catastrophizing than healthy controls. The total TSK score of the patients (without exclusion of the reversed key items) was 38.45 $(\mathrm{SD}=6.44)$. Compared with normative data about the TSK (Vlaeyen, Kole Snijders, Rotteveel et al., 1995), it appeared that $57.6 \%$ of the patients scored below, or on the same level, as the reported median of the 
Table 1. A summary of sample statistics.

\begin{tabular}{llcc}
\hline & $\begin{array}{c}\text { CLBP patients } \\
(n=66)\end{array}$ & $\begin{array}{c}\text { Healthy controls } \\
(n=30)\end{array}$ & $\begin{array}{c}\text { Group difference } \\
\text { statistics }\end{array}$ \\
\hline Age (years) & $43.88 \pm 9.85$ & $42.63 \pm 8.68$ & $\begin{array}{c}t=-0.60, p=0.55 \\
t=0.27, p=0.79\end{array}$ \\
Gender (\% male) & 53.03 & 50.00 & $t=0.72, p=0.48$ \\
Education (\%)* & & & \\
$\quad$ Low & 25.76 & 0.00 & - \\
$\quad$ Middle-high & 69.70 & 100.00 & \\
Mean duration of low back pain (years) & $10.75 \pm 9.18$ & No LBP in the past year & U \\
QBPDS & $47.70 \pm 15.52$ & $8.83 \pm 10.18$ & $t=66, p<0.001$ \\
TSK(-G) without reversed key items & $29.50 \pm 5.94$ & $23.03 \pm 4.42$ & $t=-5.33, p<0.001$ \\
PCS & $17.62 \pm 9.65$ & $11.60 \pm 8.41$ & $t=-2.95, p<0.01$ \\
\hline
\end{tabular}

QBPDS=Quebec Back Pain Disability Scale; TSK $(-G)=$ Tampa Scale for Kinesiophobia, either the version for the patient (TSK) or healthy control (TSK-G); PCS=Pain Catastrophizing Scale; CLBP=chronic low back pain.

*Education: low=lower vocational education, or below; middle-high=advanced elementary education, or higher.

TSK. This suggests that the level of fear of movement/(re)injury of the included group of CLBP patients is representative for the average CLBP population.

\section{Stimulus words}

To support the validity of the word selection, it appeared that the threatening words (mean=7.36, $\mathrm{SD}=1.78$ ) were appraised as more threatening than the neutral words (mean $=1.40, \mathrm{SD}=0.65 ; \mathrm{Z}=-8.46, p<0.001)$. CLBP patients evaluated the movement words of the implicit tasks as significantly more threatening (mean difference $=-2.85$, $t=-8.11, p<0.001$ ) than healthy controls. Patients and healthy controls did not differ in their evaluation of neutral $(\mathrm{U}=890.00$, $p=0.45$ ) or threatening (mean difference= $-0.24, t=-0.61, p=0.54$ ) words. It therefore seems that the neutral and threatening words were chosen accurately for the key-assignment, as well as that the movement words were more threatening to the CLBP patients than healthy controls.

\section{Implicit fear of movementl(re)injury in CLBP patients and healthy controls}

$E A S T$. The mean proportion of errors was $0.11(\mathrm{SD}=0.12)$ for CLBP patients, and 0.07 $(\mathrm{SD}=0.07)$ for healthy controls. The mean response time was $862(\mathrm{SD}=256)$ and 734 $(\mathrm{SD}=220)$ for CLBP patients and healthy controls respectively. In accordance with De Houwer (2003a), 3 CLBP patients (error rates of $47 \%$ and $50 \%$, and mean response time of
1741) and one healthy control (mean response time of 1649) were excluded from further analyses, since either their response times or their error rates deviated more than 3 standard deviations from the mean of their reference group.

ANOVA with response latencies of the movement trials demonstrated no effect of type of response $(\mathrm{F}(1,86)=1.22, p=0.27)$, indicating that there was no difference in response times when back-stressing movements had to be responded to with either the threatening or the neutral key. Also, no interaction effect $(\mathrm{F}(1,86)=1.64, p=0.20)$ was found between group and type of response, implying that CLBP patients and healthy controls did not differ in their EAST response time effect (for CLBP patients mean $=-3.23$, $\mathrm{SD}=237.56$ ); for healthy controls mean= 40.26, $\mathrm{SD}=110.26)$. However, there was a significant effect of group $(\mathrm{F}(1,86)=6.75$, $p<0.05)$. Post hoc comparisons revealed that CLBP patients were significantly slower than healthy controls on the compatible $(t=-3.28$, $p<0.01)$ and incompatible $(t=-2.49, p<0.05)$ movement trials. In addition, the effect of age was found to be significant $(F(1,86)=$ $7.46, p<0.01)$. There was a positive correlation $(r=0.39, p<0.01)$ between age and mean response time on the movement words, indicating that older participants responded more slowly to these words than did younger participants.

Analyses with error rates on the movement trials also demonstrated no effect of type of response $(\mathrm{F}(1,86)=0.00, p=0.98)$ or of the 
interaction between group and type of response $(\mathrm{F}(1,86)=0.51, p=0.48)$. In addition, no group main effect was found $(\mathrm{F}(1,86)=$ $0.36, p=0.55)$. This indicates that there is neither a difference between errors on compatible and incompatible movement trials, nor between groups in EAST error effect (for CLBP patients mean $=-0.03, \mathrm{SD}=0.18$; for healthy controls mean $=-0.06, \mathrm{SD}=0.16){ }^{1}$

GNAT. In accordance with Nosek and Banaji (2001), 5 CLBP patients with sensitivity scores below zero on the movement phases were removed from further analyses. In addition, GNAT data of one patient were lost because of a computer problem.

ANOVA revealed no effect of phase $(\mathrm{F}(1,84)=0.24, p=0.63)$ and no interaction effect of phase and group $(\mathrm{F}(1,84)=1.05$, $p=0.31)$. This implies that there was no difference in sensitivity when the key was pressed to movement and threatening words compared with movement and neutral words, either overall, or between groups. It can therefore be concluded that both groups did not differ with regard to their GNAT-effects (for CLBP patients mean $=0.71, \mathrm{SD}=1.17$; for healthy controls mean $=0.21, \mathrm{SD}=1.35$ ). However, a significant main effect of group was found $(\mathrm{F}(1,84)=5.41, p<0.05)$. Post hoc $t$-tests revealed that this was because patients had a significantly lower sensitivity on the incompatible phase $(t=2.84, p<0.01)$. Furthermore, significant effects of age $(\mathrm{F}(1,84)=6.96$, $p<0.05)$ and educational level $(\mathrm{F}(1,84)=4.34$, $p<0.05)$ were found. There were significant correlations between both age and educational level with sensitivity scores on the compatible $(r=-0.23, \quad p<0.05$ for age, $r=0.25, p<0.05$ for educational level) and incompatible $(r=-0.31, p<0.01$ for age, $r=0.26, p<0.05$ for educational level) movement phases. A higher age and a lower educational level were therefore associated with diminished performance on the GNAT.

\section{Relationship between implicit measures and self-report measures}

See Table 2 for an overview of the relationships between the implicit measures and selfreport measures. Results showed that the EAST response time effect was not significantly related to the EAST error effect. Also, no significant relationship existed between both EAST effects and the GNAT effect. Thus, no significant relationship was found between 2 different parameters within the EAST, nor between the EAST and the GNAT.

Examination of associations between the implicit and self-report measures solely revealed a significant positive correlation between the EAST response time effect and self-reported fear of movement/(re)injury in healthy controls. Thus, the higher healthy controls scored on self-reported fear of movement/(re)injury, the higher they also scored on implicit fear of movement/(re)injury. The other significant association between the EAST error effect and appraisal of movement words for patients was considered irrelevant due to its weakness $(r=0.27, p=0.03)$.

\section{Discussion}

The main aim of the current study was to examine whether CLBP patients displayed more implicit fear of movement/(re)injury than healthy controls, as reflected in a stronger association between back-stressing movements and the evaluation "threatening" being measured with the EAST and the GNAT. From analyses with both implicit measures, it appeared that neither CLBP patients nor healthy controls demonstrated implicit fear of movement/(re)injury. Furthermore, despite a significant difference on a self-report measure of fear of movement/ (re)injury, CLBP patients did not differ from healthy controls in implicit fear of movement/ (re)injury. Post hoc examination of the injury and rest words, which were included in the EAST for exploratory reasons, corroborated these findings. Unfortunately, these results add even more ambiguity to previous studies investigating implicit fear of movement/(re)injury (de Jong \& Peters, 2002; Goubert et al., 2003).

The second aim of the study was to investigate whether the EAST and the GNAT were related to each other, as well as to self-report measures of fear of movement/(re)injury. The 2 different EAST parameters were not related to each other, nor did these 2 EAST parameters correlate with the GNAT score. These results are in accordance with other studies that failed to find any correspondence between implicit measures, which might be due 
Table 2. Correlation matrix of implicit measures and self-report measures for fear of movement/(re)injury for patients with chronic low back pain (CLBP) and healthy controls separately.

$\begin{array}{llllll}\text { A } & \text { B } & \text { C } & \text { D } & \text { E } & \text { F }\end{array}$

Implicit measures

A EAST effect response time,

B EAST effect error,

CLBP patients (n)

Healthy controls $(n)$

CLBP patients $(n) \quad 0.05(63)$

$\begin{array}{lr}\text { Healthy controls }(n) & -0.08(29)\end{array}$

CLBP patients $(n)$

Healthy controls $(n)$

$0.17(57)$

$0.05(29)$

\begin{tabular}{|c|c|c|c|c|c|c|c|c|}
\hline & Self-report measures & & & & & & & \\
\hline$\overline{\mathrm{D}}$ & Fear of movement, & CLBP patients $(n)$ & $-0.01(63)$ & $0.03(63)$ & $0.07(60)$ & - & & \\
\hline & & Healthy controls $(n)$ & $0.40(29)^{*}$ & $-0.21(29)$ & $0.18(30)$ & & & \\
\hline $\mathrm{E}$ & Pain catastrophizing, & CLBP patients $(n)$ & $0.07(63)$ & $-0.09(63)$ & $0.11(60)$ & $0.52(66)^{* * *}$ & - & \\
\hline $\mathrm{F}$ & Word appraisal movement, & $\begin{array}{l}\text { CLBP patients }(n) \\
\text { Healthy controls }(n)\end{array}$ & $\begin{array}{r}0.19(62) \\
-0.08(29)\end{array}$ & $\begin{array}{l}0.27(62)^{*} \\
0.14(29)\end{array}$ & $\begin{array}{r}0.09(59) \\
-0.14(30)\end{array}$ & $\begin{array}{l}0.35(66)^{* *} \\
-0.10(30)\end{array}$ & $\begin{array}{r}0.18(66) \\
-0.06(30)\end{array}$ & - \\
\hline
\end{tabular}

${ }^{*} p<0.05 ;{ }^{* *} p<0.01 ;{ }^{* * *} p<0.001$. 
to low to moderate reliability of implicit measures through which actual relationships between implicit measurements may be diminished (Bosson, Swann, \& Pennebaker, 2000; Cunningham, Preacher, \& Banaji, 2001; Nosek \& Banaji, 2001; Teige et al., 2004). It is also possible that differences in the designs of the 2 tasks are responsible for the lack of a relationship (de Houwer, 2003b; Nosek \& Banaji, 2001). Although both measures aim to tap into the implicit association between movements and threat, they do this in rather different ways. First, the GNAT assumes faster responding when both movement and threat words should be responded to, whereas the EAST assumes faster responding to movement words with a key that has been extrinsically associated with threat. Secondly, the GNAT compares performance between 2 different phases, while for the EAST comparison of performance within different trials is possible. Finally, different comparison categories were employed (e.g. physical shape in the GNAT, injury and rest words in the EAST).

In general, the implicit measures were also not related to the self-report measures. These findings are in line with the MODE model, since it can be expected that the applied implicit measures did not leave enough opportunity to consciously influence the response, thereby being discordant with responses to self-report measures that are consciously controlled (Fazio et al., 1995; Greenwald et al., 1998; Nosek \& Banaji, 2001; Teige et al., 2004). The only potentially relevant relationship that appeared, namely between implicit and self-reported fear of movement/ (re)injury in healthy controls, might also be explained by this model. The relative ease of healthy controls in performing these automatic association tasks may have left sufficient recourses to deliberately generate their responses to the EAST, resulting in higher overlap between the responses on the implicit and self-report measures.

Drawing inferences from these findings is rather intricate because of one major caveat of implicit measurements; that is, their questionable reliability and validity. Recently it became clear that reliability of the EAST is poor (de Houwer, 2003a; Teige et al., 2004). Indeed, we found that Cronbach's alpha over the difference in response times between the compatible and incompatible presentation of each specific movement word, was extremely low $(\alpha=0.12, n=46)$. For the GNAT, no information concerning reliability is available from existing literature. We examined the relationship between GNAT effects computed over the first and second half of the trials, which revealed a highly significant correlation $(r=0.50, p<0.001 ; n=89)$ between both halves. This indicates moderate reliability. Due to the lack of adequate psychometric properties, especially for the EAST, it is possible that existing effects were not detected. Furthermore, for the current study we adapted the EAST and GNAT that were only previously applied to measure simple universal associations. This may have also reduced the reliability of these implicit measures.

There are several other limitations of this study that need to be taken into account. First, since CLBP patients considered these implicit tasks as more difficult to perform (as reflected in their higher error rates, lower sensitivity scores, and longer EAST response times) than healthy controls, it is possible that both groups experienced, or performed, these tasks differently. Through this, the implicit tasks might not be comparable between both groups. Secondly, participants performed the EAST prior to the GNAT. It is therefore possible, but unfortunately not verifiable, that the EAST influenced the performance on the GNAT. Thirdly, medication use and pain intensity levels were not accounted for, though it is possible that these may have influenced the response times of the CLBP patients.

In conclusion, neither CLBP patients nor healthy controls demonstrated implicit fear of movement/(re)injury on the EAST and the GNAT. Neither implicit measure was related to the other, or to self-report measures of fear of movement/(re)injury. However, the poor psychometric properties of the implicit measures used to determine fear of movement/ (re)injury should be acknowledged. Research encouraging the reliability and validity of these tasks may be warranted before they are modified and applied to complex domains, such as fear of movement/(re)injury.

\section{Acknowledgements}

This study was supported by grant 1436.0002 of the Netherlands Organisation for Health Research and Development (ZonMw). We are 
grateful to Sita van Riet of Maastricht University, and Floske de Jong, who realized the data collection. We also thank Dirk Hermans and 2 anonymous reviewers for their valuable comments on an earlier version of the manuscript. This study was made possible thanks to Jan Jochijms and Jolanda Idink of Top-Care Health Services Maastricht and Venlo.

\section{Note}

1. The same ANOVA applied to the response latencies and errors for the injury words revealed neither an effect of type of response $(\mathrm{F}(1,85)=3.72, p=0.06$ and $\mathrm{F}(1,86)=0.37, p=$ 0.54 , respectively) nor an interaction between group and type of response $(\mathrm{F}(1,85)=2.23$, $p=0.14$ and $\mathrm{F}(1,86)=2.57, p=0.11$, respectively). While for the error rates none of the between subject variables was significant (all $p>0.12$ ), for the response times a significant effect was found for group $(\mathrm{F}(1,85)=4.84$, $p<0.05)$ and age $(\mathrm{F}(1,85)=11.23, p<0.01)$. Patients were significantly slower than healthy controls on the compatible injury trials $(t=-2.50, p<0.05)$, and there was a positive correlation between age and mean response time on injury words $(r=0.36, p<0.01)$. The same ANOVA applied to the response latencies and errors for the rest words revealed neither an effect of type of response $(\mathrm{F}(1,86)=0.01$, $p=0.92$ and $\mathrm{F}(1,86)=0.37, p=0.54$, respectively) nor an interaction between group and type of response $(\mathrm{F}(1,86)=0.38, p=0.54$ and $\mathrm{F}(1,86)=0.06, p=0.81$, respectively). While for the error rates none of the between subject variables was significant (all $p>0.10$ ), for the response times a significant effect was found for group $(\mathrm{F}(1,86)=6.83, p<0.05)$ and age $(\mathrm{F}(1,86)=7.79, p<0.01)$. Patients were significantly slower than healthy controls on both the compatible $(t=-4.23, p<0.001)$ and incompatible $(t=-2.45, p<0.05)$ rest trials, and there was a positive correlation between age and mean response time on rest words $(r=0.33$, $p<0.01)$.

\section{References}

Al-Obaidi, S. M., Al-Zoabi, B., Al-Shuwaie, N., Al-Zaabie, N., \& Nelson, R. M. (2003). The influence of pain and pain-related fear and disability beliefs on walking velocity in chronic low back pain. International Journal of Rehabilitation Research, 26(2), 101-108.

Boersma, K., Linton, S. J., Overmeer, T., Jansson, M., Vlaeyen, J. W. S., \& de Jong, J. (2004). Lowering fear-avoidance and enhancing function through exposure in vivo; a multiple baseline study across six patients with back pain. Pain, 108(1-2), 8-16.
Bosson, J. K., Swann, W. B., \& Pennebaker, J. W. (2000). Stalking the perfect measure of implicit self-esteem: the blind men and the elephant revisited? Journal of Personality and Social Psychology, 79(4), 631-643.

Burton, A. K., McClune, T. D., Clarke, R. D., \& Main, C. J. (2004). Long-term follow-up of patients with low back pain attending for manipulative care: outcomes and predictors. Manual Therapy, 9, 30-35.

Crombez, G., \& Vlaeyen, J. W. S. (1996). The Pain Catastrophizing Scale: Unpublished authorized Dutch/Flemish translation.

Cunningham, W. A., Preacher, K. J., \& Banaji, M. R. (2001). Implicit attitude measures: consistency, stability, and convergent validity. Psychological Science, 12(2), 163-170.

de Houwer, J. (2002). The Implicit Association Test as a tool for studying dysfunctional associations in psychopathology: strength and limitations. Journal of Behavior Therapy, 33, 115-133.

de Houwer, J. (2003a). The Extrinsic Affective Simon Task. Experimental Psychology, 50(2), 77-85.

de Houwer, J. (2003b). A structural analysis of indirect measures of attitudes. In J. Musch \& K. C. Klauer (Eds), The Psychology of Evaluation: Affective Processes in Cognition and Emotion (pp. 219-244). Mahwah: Lawrence Erlbaum Associates, Publishers.

de Jong, J. R., Vlaeyen, J. W. S., Onghena, P., Goossens, M. J. E. B., Geilen, M., \& Mulder, H. (2005). Fear of movement/(re)injury in chronic low back pain: education of exposure in vivo as mediator to fear reduction? Clin J Pain, 21(1), 9-17.

de Jong, P. J., Pasman, W., Kindt, M., \& Hout, v. d. M. A. (2001). A reaction time paradigm to assess (implicit) complaint-specific dysfunctional beliefs. Behaviour Research and Therapy, 39, 101-113.

de Jong, P. J., \& Peters, M. (2002). Implicit attitudes toward pain and injury in chronic low back pain patients. Paper presented at the conference of the European Association of Behavioural and Cognitive Therapies, September, Maastricht, The Netherlands.

Fazio, R. H., Jackson, J. R., Dunton, B. C., \& Williams, C. J. (1995). Variability in automatic activation as an unobtrusive measure of racial attitudes: a bona fide pipeline? Journal of Personality and Social Psychology, 69, 1013-1027.

Fazio, R. H., \& Olson, M. A. (2003). Implicit measures in social cognition research: their meaning and use. Annual Review of Psychology, 54(1), 297-327.

Fritz, J. M., \& Irrgang, J. J. (2001). A comparison of a modified Oswestry Low Back Pain Disability Questionnaire and the Quebec Back Pain Disability Scale. Physical Therapy, 81(2), 776-788.

Geisser, M. E., Haig, A. J., \& Theisen, M. E. (2000). Activity avoidance and function in persons with chronic back pain. Journal of Occupational Rehabilitation, 10(3), 215-227. 
Gheldof, E., de Jong, P. J., Vinck, J., \& Houben, R. M. A. (2004). Attitudes towards physical activity: the role of implicit versus explicit associations. In G. J. Asmundson, J. W. S. Vlaeyen \& G. Crombez (Eds), Understanding and Treating Fear of Pain. Oxford: Oxford University Press.

Goubert, L., Crombez, G., Hermans, D., \& Vanderstraeten, G. (2003). Implicit attitudes towards pictures of back-stressing activities in pain-free subjects and patients with low back pain: an affective priming study. European Journal of Pain, 7, 33-42.

Goubert, L., Crombez, G., \& Lysens, R. (2005). Effects of varied-stimulus exposure on overpredictions of pain and behavioural performance in low back pain patients. Behaviour Research and Therapy, 43(10), 1347-1361.

Goubert, L., Crombez, G., Van Damme, S., Vlaeyen, J. W. S., Bijttebier, P., \& Roelofs, J. (2004). Confirmatory factor analysis of the Tampa Scale for Kinesiophobia: invariant two-factor model across low back pain patients and fibromyalgia patients. The Clinical Journal of Pain, 20(2), 103-110.

Greenwald, A. G., McGhee, D. E., \& Schwartz, J. L. K. (1998). Measuring individual differences in implicit cognition: the Implicit Association Test. Journal of Personality and Social Psychology, 14(6), 1464-1480.

Hofmann, W., Gawronski, B., Gschwendner, T., Le, H., \& Schmitt, M. (2005). A meta-analysis on the correlation between the Implicit Association Test and explicit self-report measures. Personality and Social Psychology Bulletin, 31(10), 1369-1385.

Houben, R. M. A., Gijsen, A., Peterson, J., de Jong, P. J., \& Vlaeyen, J. W. S. (2005). Do health care providers' attitudes towards back pain predict their treatment recommendations? Differential predictive validity of implicit and explicit attitude measures. Pain, 114(3), 491-498.

Houben, R. M. A., Leeuw, M., Vlaeyen, J. W. S., Goubert, L., \& Picavet, H. S. J. (2005). Fear of movement/injury in the general population: factor structure and psychometric properties of an adapted version of the Tampa Scale for Kinesiophobia. Journal of Behavioural Medicine, 28(5), 415-424.

Kopec, J. A., Esdaile, J. M., Abrahamowicz, M., Abenheim, L., Wood-Dauphinee, S., \& Lamping, D. L., et al. (1995). The Quebec Back Pain Disability Scale: measurement properties. Spine, 20(3), 341-352.

Lethem, J., Slade, P. D., Troup, J. D., \& Bentley, G. (1983). Outline of a fear-avoidance model of exaggerated pain perception: I. Behaviour Research and Therapy, 21(4), 401-408.

Linton, S. J., Buer, N., Vlaeyen, J. W. S., \& Hellsing, A.-L. (1999). Are fear-avoidance beliefs related to the inception of an episode of back pain? A prospective study. Psychology and Health, 14(6), 1051-1059.

Miller, R. P., Kori, S. H., \& Todd, D. D. (1991). The Tampa Scale for Kinisophobia, Unpublished report. Tampa, FL.
Nosek, B. A., \& Banaji, M. R. (2001). The Go/NoGo association Task. Social Cognition, 19(6), 625-664.

Picavet, H. S., Vlaeyen, J. W. S., \& Schouten, J. S. (2002). Pain catastrophizing and kinesiophobia: predictors of chronic low back pain. American Journal of Epidemiology, 156(11), 1028-1034.

Psychology Software Tools, Inc. (1996-2003). Serial Response Box.

Roelofs, J., Goubert, L., Vlaeyen, J. W. S., \& Crombez, G. (2004). The Tampa Scale for Kinesiophobia: further examination of psychometric properties in patients with chronic low back pain and fibromyalgia. European Journal of Pain, 8(5), 495-502.

Roland, M., \& Morris, R. (1983). A study of the natural history of back pain. Part I: development of a reliable and sensitive measure of disability in low back pain. Spine, 8, 141-144.

Schneider, W. (1996). MEL Professional. Pittsburg: The Combustion Institute.

Schoppink, L. E. M., van Tulder, M. W., Koes, B. W., Beurskens, A. J. H. M., \& de Bie, R. (1996). Reliability and validity of the Dutch adaptation of the Quebec Back Pain Disability Scale. Physical Therapy, 76(3), 268-275.

Sullivan, M. J. L., Bishop, S. R., \& Pivik, J. (1995). The Pain Catastrophizing Scale: Development and validation. Psychological Assessment, 7(4), 524-532.

Swinkels-Meewisse, E. J. C. M., Swinkels, R. A. H. M., Verbeek, A. L. M., Vlaeyen, J. W. S., \& Oostendorp, R. A. B. (2003). Psychometric properties of the Tampa Scale for kinesiophobia and the fear-avoidance beliefs questionnaire in acute low back pain. Manual Therapy, 8(1), 29-36.

Swinkels-Meewisse, I. E. J., Roelofs, J., Schouten, E. G. W., Verbeek, A. L. M., Oostendorp, R. A. B., \& Vlaeyen, J. W. S. (2006). Fear of movement/(re)Injury predicting chronic disabling low back pain: a prospective inception cohort study. Spine, 31(6), 658-664.

Teige, S., Schnabel, K., Banse, R., \& Asendorpf, J. B. (2004). Assessment of multiple implicit selfconcept dimensions using the Extrinsic Affective Simon Task (EAST). European Journal of Personality, 18, 495-520.

Van Damme, S., Crombez, G., Bijttebier, P., Goubert, L., \& Van Houdenhove, B. (2002). A confirmatory factor analysis of the Pain Catastrophizing Scale: invariant factor structure across clinical and non-clinical populations. Pain, 96(3), 319-324.

Van Damme, S., Crombez, G., Vlaeyen, J. W. S., Goubert, L., Van den Broeck, A., \& Van Houdenhove, B. (2000). De Pain Catastrophizing Scale: Psychometrische karakteristieken en normering. [The Pain Catastrophizing Scale: Psychometric characteristics and norms.] Gedragstherapie, 33(3), 209-220.

Van Nieuwenhuyse, A., Somville, P. R., Crombez, G., Burdorf, A., Verbeke, G., \& Johannik, K., et al. (2006). The role of physical workload and pain related fear in the development of low 
back pain in young workers: evidence from the BelCoBack Study; results after one year of follow up. Occupational and Environmental Medicine, 63(1), 45-52.

Vlaeyen, J. W. S., de Jong, J., Geilen, M., Heuts, P. H. T. G., \& van Breukelen, G. (2002). The treatment of fear of movement/(re)injury in chronic low back pain: Further evidence on the effectiveness of exposure in vivo. Clinical Journal of Pain, 18(4), 251-261.

Vlaeyen, J. W. S., de Jong, J., Sieben, J. M., \& Crombez, G. (2002). Graded exposure in vivo for pain-related fear. In D. C. Turk \& R. J. Gatchel (Eds), Psychological Approaches to
Pain Management. A Practitioner's Handbook. New York: The Guilford Press.

Vlaeyen, J. W. S., Kole Snijders, A. M. J., Rotteveel, A. M., \& Ruesink, R., et al. (1995). The role of fear of movement/(re)injury in pain disability. Journal of Occupational Rehabilitation, 5(4), 235-252.

Vlaeyen, J. W. S., Kole-Snijders, A. M. J., Crombez, G., Boeren, R., \& Rotteveel, A. M. (1995). The Tampa Scale for Kinesiophobia TSK, Dutch authorized version.

Waddell, G. (2004). The epidemiology of back pain. In G. Waddell (Ed.), The Back Pain Revolution (pp. 71-89). Edinburgh: Churchill Livingstone. 